cal; that while taking the latter he would do well to perfect his technique in the performance of his paracenteses. If unable to take more than one appointment, I would like to remind him that it is not necessary to be a resident interne to pick up additional knowledge in the various branches of medicine-out-patient departments give similar opportunities for less fortunately placed young men, and are anxious to procure their services.

\section{OClinital Bepartment,}

\section{AN UNUSUAL NEPHRITIS.}

BY F. V.AN NÜYs, M.D., Weston, Mass.

MrS. A. C., aged 22, entered the Waltham Hospital July 18, 1919," remaining there 43 days. She reëntered May 29, 1920, and died June 30,1920 . She was under close observation for nearly a year.

Her family history is negative except that her brother recently shows albumen in the urine after suffering for months from "indigestion." No diseases in childhood except measles. Excellent health, but for occasional sore throats, up to childbirth four years ago. No miscarriage.

Present Illness: Since her child was born, she had fair health up to the summer of 1918. Then, without ascertainable cause, she gradually developed nephritic symptomspallor, headaches, oedema of hands and feet, occasional nausea and vomiting, dizziness, dyspnea on exertion, and failing eyesight up to almost complete blindness. For the last six months she had suffered from paresis and partial anaesthesia of the left arm and leg. In June and July of 1919 she seemed close to death. She entered the hospital with orthopnea, anasarca, pernicious vomiting, semi-coma, partial paralysis of left half of body, and nearly complete blindness; in short, impending uremia.

Physical Examination: A small, pale, emaciated though bloated woman. Throat, tongue, and ears are negative. Teeth decayed. Skin pale. Pupils equal and react normally. Kneejerks lively. Left ankle clonus. Lungs negative, save for moist râles at bases. Heart 19 cm. wide on percussion; action regular and rapid; sounds forcible; a blowing systolic murmur at apex transmitted to axilla; aortic second increased. Blood pressure 220/120 (this later fell and kept about 180/115). Abdomen full and soft; no masses, tenderness, or spasm; spleen not palpable; liver sixth rib to costal margin. Eye grounds showed choroidoretinitis so marked that little normal retina could be found. She could make out the form of anyone standing beside her bed.

Urine: The 24-hour quantity varied from 250 to 1500 c.c., usually about 800 c.c. $\mathbf{S p}$. gravity 1002 to 1010. Reaction acid. Sugar absent. Albumen always a heavy trace ( $8 \%$ ). Mieroscopically a rather heavy sediment. Many granular, hyaline, and cellular casts. A few waxy casts. Many red blood cells, mostly shadow forms. Little fat seen. Later on in the disease the casts came in showers.

Treatment: For almost a month usual methods of treatment were tried with very little benefit. She remained in about the same condition. She was put on absolute rest, low protein (40 to $50 \mathrm{gm}$. protein daily), and as high fat and carbohydrate diet as possible. The caloric tables showed that she received insufficient food because of anorexia and uncontrollable vomiting. I believe that free daily movements of the bowels, and sweating when her strength permitted, enabled her to live through the first month in the hospital.

Caffein, diuretin, digitalis, nitroglycerin, and thyroid extract were tried at one time or another with no appreciable effect.

Finally Fischer's treatment was begun on August 16, 1919, with immediate and remarkable benefit. She received his hypertonic salt solution (sod. chloride 14 gm., sod. carbonate $10 \mathrm{gm}$., and water 1000 c.c.) daily by the Murphy drip in the rectum, and alkalies and sodium chloride freely by mouth. In the next ten days her uremic symptoms disappeared. The anasarca lessened gradually.. The 24-hour quantity of urine rose to 1500 c.c. and above. The headache, vomiting and stupor cleared away. The blood pressure fell to 185/115 and remained thereabouts for many months. Appetite and digestion returned. She could sleep on one pillow and her previous dyspnea was wholly relieved. Eyesight improved so that she could read the headlines of a "yellow" newspaper, although the eyegrounds looked as bad as before.

Fischer's treatment gave so much discomfort that in two weeks the patient chose to diseontinue it wholly and return home in an invalid but comfortable condition. At home she was put on the low protein diet. 
Laboratory Findings: For the first few weeks little work was done in kidney or other tests because death was expected daily.

Blood: Hemoglobin $35 \%$. Red cells 2,840,000. White cells 9000 per cubic $\mathrm{mm}$. The smear was typical of secondary anaemia No blasts. No stippling. Feces negative to graiac test.

Wassermann tests of both blood and spinal fluid were negative.

A number of modified Schlayer tests were done, all with about the same result. The following (Diagram 1) was taken after the Fischer treatment had improved her condition enough to allow her to take sufficient food and liquid to make the test worth while.

\begin{tabular}{|c|c|c|}
\hline \multicolumn{3}{|c|}{ DIAGRAM I. } \\
\hline Time of $D_{A Y}^{\prime}$ & c. c. & Sp. G. \\
\hline 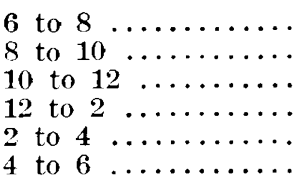 & $\begin{array}{l}110 \\
290 \\
240 \\
300 \\
250 \\
110\end{array}$ & $\begin{array}{l}1010 \\
100 \Omega \\
1004 \\
1004 \\
1004 \\
1002\end{array}$ \\
\hline 6 P.M. to 6 A.M. $\ldots$ & 1000 & 1008 \\
\hline Total, Day ....... & 1300 & \\
\hline Total, 24 hours .... & 2300 & \\
\hline $\begin{array}{l}\text { Intake of fluid } \ldots . . \\
\text { Intake of NaCl was } \\
\text { put was } 5 \mathrm{gm} \text {. } \\
\text { Output of total solid }\end{array}$ & $\begin{array}{l}2000 \\
9 \mathrm{gm} .\end{array}$ & out- \\
\hline
\end{tabular}

Impression: ITedinger's and Schlayer's diet, used in the above test, puts a heavy load of elimination upon the diseased kidneys. In this case the water elimination was excellent-a vast improvement in function over that prior to the Fischer treatment. The fact of the output being greater than the intake was probably due to the disappearing anasarca, because subsequent similar tests failed to give this feature. The function of water elimination remained elastic all that fall and winter.

On the other hand, the kidneys' ability to concentrate urine is manifest, and confirmed by five subsequent tests. Apparently the kidneys showed the height of this ability in the early forenoon, a low steady performance from 10 to 4 , and almost nothing from 4 to 6 -namely, a function which fails as the day progresses.

In theory the subnormal output of total solids, the constantly low specific gravity, the incomplete elimination of $\mathrm{NaCl}$, combine to make a diagnosis of tubular rather than one of vascular hyposthenuria. Here, however, the later post-mortem findings prove that the hyposthenuria was not wholly one or the other, but both combined.

The phenolsulphonephthalein test was given during the year six times in all. Not once did a trace of the dye appear in the urine at the end of two, or of 24 , hours. It may be that this patient's body destroyed the dye with peculiar rapidity and completeness, and that, if her body destruction had been $20 \%$ to $40 \%$ of the dye, as in the average person, she might have eliminated some of it in her urine. If, as has been said, the red test is a reliable index of kidney elimination we should expect the speedy death of the patient. This case, however, illustrates the fact that the kidney may eliminate one substance with difficulty (salt), another easily (water), and a third not at all (red dye). Prognosis cannot be based on one functional test.

The blood nitrogen and sugar determinations were made by Dr. F. L. Burnett of Boston. The blood was taken after a six-hour fast. The protein intake at no time exceeded $55 \mathrm{gm}$. in the 24 hours.

$$
\text { NON-PROTEIN NITROGEN OF THE BLOOD. }
$$

\section{X.P.N. \\ Ngm. per \\ IOO ce blood.}

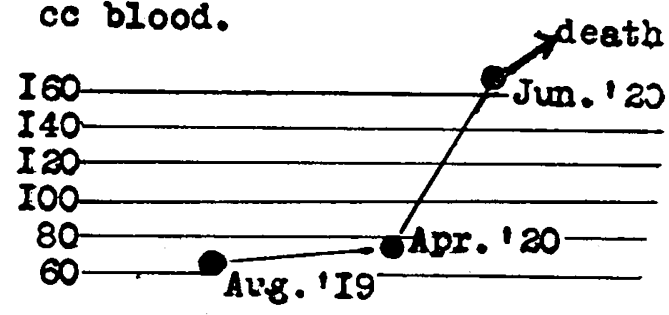

(Normal-20 to $30 \mathrm{mgm}$. per 100 c.c. blood.)

The first. N-PN. was taken while, under Fischer's treatment, her uremic symptoms were fast disappearing. During the winter at home she led a semi-invalid life with periods of comparatively little sickness. Twice she was able to go sled riding. In February she had a slight attack of influenza, after which her uremic syinptoms gradually reappeared. The last N-PN. reading foretold her approaching death.

BLOOD SUgar.

July, $1919 \ldots \ldots \ldots \ldots \ldots \ldots \ldots \ldots \ldots .22 \%$
April, $1920 \ldots \ldots \ldots \ldots \ldots \ldots \ldots .12 \%$
June, $1920 \ldots \ldots \ldots \ldots \ldots \ldots \ldots \ldots .07 \%$
(Normal blood sugar, $0.7 \%$ to $0.11 \%$ )

The high blood sugar was discovered by accident. The cause is unknown beyond the fact 
that the blood of chronic nephritics sometimes shows a higher sugar content than normal. The lower contents in April and June are due probably to partial starvation in the terminal stage of her disease.

The patient had become so accustomed to her chronic uremic poisoning that it seemed she might live indefinitely. Finally, however, she developed a right-sided purulent pleurisy and died having the same symptoms with which she had entered the hospital nearly a year before.

Permission for a partial autopsy was obtained. The kidneys were small, firm, pale, with adherent capsules. Weight, $126 \mathrm{gm}$. The report of the pathologist, Dr. F. L. Burnett, is given.

"In sections of the kidneys almost one-half of the tissue is composed of fibrous cells. Fully one-half of the glomeruli are obliterated, and are evident only by a contracted mass of fibrous material which often presents hyaline degeneration. Many of the convoluted tubules, too, are obliterated, and those that remain show a hydropic degeneration. The descending and ascending loops of Henle are also obliterated; although more of these are apparent than any other parts of the tubule. Numerous hyaline and timely granular casts are apparent also. The capsule of the kidney is moderately thickened and the arteries which sometimes present a slightly thickened media are in general not abnormal. The tissue does not contain a great deal of fat. Scattered generally through the tissues are numerous areas made up of lymphocytes, but they are irregular in shape and areas of necrosis are not apparent within them."

The patient's clinical history might be explained from this picture of the kidney tissue. Apparently many glomeruli were destroyed and others spared. Those tubules which escaped destruction were badly crippled. The tubules on the whole suffered more than the glomeruli. The patient for a good while had a barely sufficient kidney parenchyma which gradually was choked out by the increase and spread of fibrous and scar tissue.

\section{NON-TUBERCULOUS COMPLICATIONS OF PULMONARY TUBERCULOSIS.}

By Herbert F. Gammons; M.D., Dallas, Texas.

THE differential diagnosis between pulmonary tuberculosis and other conditions simulating this disease in its local reflex and toxic symp- toms will be in all probability, a problem for years to come.

The problem is made more difficult when we realize that many tuberculous suspects have in addition to an active or: healed tuberculous focus an active focus of infection due to other organisms than the tubercle bacillus either in the lungs or in some other organ. However, in patients with sputum containing bacilli there are found one, two or more conditions which cause symptoms that are blamed on the tuberculous condition and which influence the prognosis and treatment greatly if discovered and remedied.

It is unfortunate that so many physicians after finding a positive sputum or physical signs in the chest, stop making further examination of the patient and feel that all symptoms such as temperature, chills, etc., are due to the tuberculosis. The natural course of a tuberculous infection is toward improvement, and in any given case of apparent good resistance, with a eontinuation of symptoms after proper rest and hygienic treatment for the tuberculous condition has been in effect, some other focus of infection should be sought out and treated.

This does not mean that reckless removal of tonsils and teeth is adrocated in patients with lowered resistance. The probable improvement must be weighed against the probable reaction following operations. Nature, however, is burdened with infections and conditions, especially mental, in addition to the tuberculosis, which rin often he remedied, which in many cases have prevented an arrest of the disease.

Maay, times a post-mortem examination has shown there may be superimposed infection in the lungs, the tuberculous infection while discharging a few bacilli being the slightest in extent and the influenzal or pneumonic condition being of greater extent and severity. Often the body tissues need building up, especially the blood, and occasionally, I have seen patients in whom a marked shortness of breath was apparently due to deficient oxygen-carrying properties of the blood and cleared up under hypodermic iron injec. tion. It has been the habit with many physicians once a diagnosis has been made of pulmonary tuberculosis not to look further into the case, but to blame any and all symptoms on tuberculosis, and in some instances this attitude has been the cause of deaths on account 